\title{
Epidemiological Factors Influencing Dog Bites in Srinagar
}

\author{
Thahaby $\mathrm{N}^{1 *}$, Akand $\mathrm{AH}^{2}$, Hamdani $\mathrm{SA}^{3}$, Bhat $\mathrm{AH}^{4}$, Maryam $\mathrm{M}^{5}$ and Ayman \\ $\mathbf{N}^{6}$ \\ 1,2,3,4,6 Division of Veterinary and Animal Husbandry Extension, Sher-e-Kashmir University of \\ Agricultural Sciences and Technology of Kashmir, India \\ ${ }^{5}$ Division of Soil and Water conservation engineering, India
}

\section{Editorial}

Volume 5 Issue 1

Received Date: March 02, 2021

Published Date: March 09, 2021

DOI: $10.23880 /$ eij-16000184

*Corresponding author: Namera Thahaby, PhD Scholar, Division of Veterinary and Animal Husbandry Extension, FVSc \& AH, SKUAST-Kashmir, Srinagar, J \& K, India, Email: nimrazahbi@gmail.com

Keywords: Epidemiology; Rabies; Dog Bites; Srinagar

Abbreviations: SMC: Srinagar Municipal Corporation.

\section{Introduction}

Men's dominant ally, best defense defendant, therefore, the pre-eminent peril detector, dogs became a threat for the humanity inflicting a fatal disease of rabies. Dog bites and open garbage dumps became additional and apparent and are serious and sometimes underestimated public health dilemma in the Kashmir region. The aesthetic and psychosociological consequences of trauma caused by a dog bites repeatedly burden the standard of lifetime pertaining to the affected persons and their family. Keeping in sight the importance of this Zoonotic disease, the current study was being planned to hold out with the subsequent objectives:

- To study the epidemiological pattern of dog bites and the occurrence of rabies in humans.

- To study the perception of rabies Vis-a-Vis dog bite exposure among humans.

- To study about the major factors associated with increased dog population Vis-a-Vis spread of rabies

The presentstudy was carried in Srinagar district. Diverse sampling plan/data collection strategy was formulated to fulfill the set of objectives. Epidemiological pattern and occurrence of dog bites was collected from the secondary information. As all such cases are shouldered by the most reputed and super specialist hospital in the Valley i.e. Shri Maharaja Hari Singh hospital, the information recorded for such cases was collected from this institute. Regarding perception of people interview schedule was formulated. To exploit the diversity of population response, all the four zones were considered for the present investigation. About the major factors associated with increased dog population two sources i.e, primary and secondary sources had been utilized for identifying the likely factors responsible for increased dog population. These factors primarily incorporated garbage management, specific control measures for dog population by stakeholders and perception of people. Secondary source includes Srinagar Municipal Corporation, for collecting the relevant information [1].

\section{Salient Findings of the Study}

The major findings of the study were as follows:

\section{Epidemiological Pattern of Dog Bites and Occurrence of Rabies in Humans}

- West zone had recorded the highest number of cases, then south zone, followed by north zone and the east zone.

- Majority victims were males followed by females. Most of them belonged to 30-40 year old group, followed by 20-30, 1-20 and so on. Utmost cases were reported in evening and in the same day followed by morning. The time of exposure of victims was evening except for males it was at night. The bulk number of cases had bite on legs. Majority males had bites on face and females on hands, arms and shoulders. Majority had category 3 bites followed by category 2 . The summer season had also recorded the highest number of cases followed by autumn season irrespective of each determinant and zones.

- The ARC of SMHS has recorded two deaths in the year 2017.

Perception of Rabies Vis-a-Vis Dog Bite Exposure 


\section{Epidemiology International Journal}

\section{Humans}

- The greater parts of respondents had heard of rabies and were awake of its spread through dog bites; however they lacked the information about the other animals transmitting rabies. This faction has enhanced communication and information regarding what is happening in their dwelling, counting dog bites as well [2].

- Bite was being mentioned by most of the respondents as a means of transmission but only some of the respondents mentioned scratches and licking as the method of transmission. This could be due to lack of complete acuity of the disease rabies.

- In our community rabies is well-known as mad dog (halkaer houn) which is allied through aggression. Aggression was thus known by most of the respondents which is in stroke amid the verity that furious form of rabies is widespread in animals.

- Regarding about the treatment, the majority were aware that the SMHS hospital provides vaccines and the respondents didn't choose any traditional methods.

- Some respondents knew about the need of prompt washing of the wound by water and soap. Victims would seek medical attention, potentially due to fear of rabies.

- The good level of knowledge amongst the non-victims may be due to numerous reports of dog's bites in Srinagar plus they were more educated.

- In case of victimized people less had learned of rabies and its transmission showing that rabies information and education is necessary for Srinagar. The maximum menace of rabies is probable to fall on the mainly susceptible sectors of society, particularly poor members with slight or no proper education.

- Furthermore the attitude of the non-victimized and victimized people was positive. The bulk of respondents believed that stray dogs are a public health problem in Srinagar.

\section{Major Factors Associated with Increased Dog Population Vis-a-Vis Spread of Rabies}

- Regarding the major factors associated with increases dog population the respondents believed that open garbage dumps are a public health barrier in the area and commence to stray dog proliferation. Also combined rabies control measures coupling dog population control, removal of dog free roaming and proliferation must be fulfilled.

- Even if the SMC is working meticulously in the field to guarantee incorporated and scientific solid waste management, yet the method needs proper segregation of waste.

- Till date around 2,000 sterilizations were conducted and also around 2,000 stray dogs were administered the antirabies vaccine, however this is too less in comparison with the total population of dogs and still the ballot of dogs from the particular zones of Srinagar is deficient.

\section{Conclusion}

About all those diseases that attack human's rabies is an example of the best known. Its inimitable infamy is bizarre when assessed on its influence medially, on the human society particularly Medicaid due to lack of discernment. The lack of complete perception might decipher into higher mortality linked to rabies. There is a need for sensitization of people so that their information can be improved and their optimistic attitude could be translated into apt practices for prevention/ control of rabies $[3,4]$. It is vital to note that merely looking at the dog bite incidents does not openly imitate the peril of death caused by rabies. Even as conditions such as dog human ratios as well as the number of bite incidents are significant, aspects such as socioeconomic status along with the convenience of getting treatment subsequent a dog bite are possibly most applicable when estimating peril of deaths caused by dog bites. Moreover OGDs are a public health obstacle in the Srinagar area and they commence to stray dogs proliferation. The easy availability of food rendered by the scraps in the garbage not only enhances fertility in dogs, but scavenging makes dogs more prone to attack people. Dogs that get free food from the garbage dropped behind by bakeshops, abattoirs don't see people as providers of food and are major likely to attack them. The over-population of dogs is therefore produced and supported by the profusion of assets humans endow with, so that it is, in sagacity, a 'manmade' dilemma. Till date only around 2,000 sterilizations were conducted and also around 2,000 stray dogs were administered the anti-rabies vaccine, however this is too less in comparison with the total population of dogs and still the ballot of dogs from the particular zones of Srinagar is deficient.

\section{Acknowledgement}

Thankfulness can by no means be articulated in words. I am thankful to god, devoid of whom all else counts for zilch. There are numerous hands and hearts behind this effort. I would like to utter my genuine admiration to my mentor Dr.Afzal Hoque Akand (Assistant professor of Division of Veterinary \& Animal Husbandry Extension), whose precious advice and insight I could not have completed without, I can't thank you enough. I am massively grateful to Dr. Abdul Hai Bhat for his direction, support and endurance for the conclusion of this study. To my advice-giving member Dr. Shabeer Ahmad Hamdani (Assistant professor of Division of Veterinary \& Animal Husbandry Extension), for his incessant support and guidance in every step of this journey, I am 


\section{Epidemiology International Journal}

perpetually grateful.

\section{References}

1. Lone KS, Bilquees S, Khan MS, Haq IU (2014) Analysis of dog bites in Kashmir: An unprovoked threat to human population. National Journal of Community Medicine 5(1): 66-68.

2. Hasan MU (2015) Kashmir: 20 rabies deaths, 80,000 dogs bite cases in 5 years. The Greater Kashmir.

3. Ain SN, Khan SMS, Azhar M, Haq S, Bashir K (2018) Epidemiological profile of animal bite victims attending an antirabies clinic in district Srinagar, Kashmir. JMSCR 6(3): 599-603.

4. Sambo M, Lembo T, Cleaveland S, Ferguson H, Sikana L, et al. (2014) Knowledge, attitudes and practices (KAP) about Rabies prevention and control: A community survey in Tanzania. J Negl Trop Dis 8(12): 3310. 